\title{
Comparison of IRI_PLAS and IRI_2012 model predictions with GPS_TEC measurements in different latitude regions
}

\author{
Salih Alçay ${ }^{1, *}$, Gurkan Oztan ${ }^{1}$, Huseyin Zahit Selvi ${ }^{1}$ \\ 1 Necmettin Erbakan University, Geomatics Engineering Department, Konya, Turkey \\ Article history \\ Received November 17, 2016; accepted April 5, 2017. \\ Subject classification: \\ GPS, IRI_2012, IRI_PLAS, IGS, TEC.
}

\begin{abstract}
The International Reference Ionosphere (IRI) is an empirical model for providing ionospheric parameters, including Total Electron Content (TEC), electron density, electron and ion temperature etc., in the altitude range from $50 \mathrm{~km}$ to $2000 \mathrm{~km}$. Since the IRI model is limited up to $2000 \mathrm{~km}$, IRI_PLAS model, plasmasphere extension of the IRI model, was proposed by the researchers. This paper investigates the TEC prediction performance of IRI_PLAS and IRI_2012 models by comparing GPS TEC data, in different latitude regions for magnetically active and quiet days. TEC data over 9 International GNSS Service (IGS) stations, located in different latitude regions, are used for the comparison. Evaluation of the diurnal results reveals good agreement with correlation coefficient $>0.9$ between GPS_TEC and empirical models for the quiet day irrespectively of the latitudinal data used. However, while the differences are not relatively large in most part of the active days, they reach high level, above $30 \mathrm{TECu}$, in some parts of the days.
\end{abstract}

\section{Introduction}

The ionosphere is a part of the Earth's atmospheric region where the enough ionized molecules and free electron density affect the propagation of radio frequency electromagnetic waves. Since they are much lighter than the free ions, free electrons mostly affect the propagation. Thus ionospheric total electron content (TEC) is of great importance for many study areas including space based observation systems, communication systems and space weather studies [Liu and Gao 2004]. Ionospheric free electron density changes because of regular (diurnal period of earth, season etc.) and irregular (ionospheric and geomagnetic storms, traveling ionospheric disturbances (TIDs) etc.) variations [Spoelstra 1996]. The widespread effect of the ionosphere on various areas and regular-irregular changes in the structure of the ionosphere have made the ionospheric studies popular subject in recent years
[Adebiyi et al. 2016, Paul et al. 2016]. In order to examine the structure and behavior of the ionosphere, continuous monitoring is crucial. For doing this, empirical models and GPS based TEC measurements are used. Empirical models can provide reliable simulation data for effective ionospheric study and forecasting [Akala et al. 2015]. For this purpose, several empirical models like International Reference Ionosphere (IRI) [Bilitza 2001], Parameterized Ionospheric model (PIM) [Daniell et al. 1995], Parameterized, real time ionospheric specification model (PRISM) [Daniel and Brown 1995], Semi-Empirical Low Latitude Ionospheric Model (SLIM) [Anderson et al. 1987], Field Line Inter Hemispheric Plasma Model (FLIP) [Scali et al. 1997], Thermosphere-Ionosphere General Circulation Model (TIGCM) [Emery et al. 1996], Utah State University Global Assimilation of Ionospheric Measurements (USA_GAIM) [Scherliess et al. 2006], Bent model [Bent and Llewelly 1973], NeQuick model [Alcay et al. 2014], Sheffield University Plasmasphere Ionosphere Model (SUPIM) [Bailey et al. 1997] have been developed. Among these models, IRI which is regularly being improved and updated, is being widely used. Many studies have focused on the performance of IRI_2012 model [Leong et al. 2015, Tariku 2015, Rice and Sojka 2015, Kumar et al. 2014 and many others]. Historical comparison of IRI and early ionograms are given in Rice and Sojka [2015]. Tariku [2015] discussed the performance of the latest version of the IRI [IRI_2012] model for estimating the vertical total electron content (VTEC) variation over Ethiopian regions during the rising phase of solar cycle 24 (2009-2011). According to the results, although the model overestimates VTEC values for most hours, it generally performs well in estimating diurnal VTEC values, particularly just after the midnight hours (0 UT-3 UT). 
Since the IRI model specifies the ionosphere only up to $2000 \mathrm{~km}$, it is necessary to extrapolate the ionosphere to the higher altitudes. For this reason, researchers proposed IRI_PLAS model, one of the possible candidate model for plasmasphere extension of IRI model [Gulyaeva and Bilitza 2012, Zakharenkova et al. 2015, Arikan et al 2015]. Arikan et al. [2015] introduced a user friendly space weather service (URL-1), providing many output products. One of them is Total Electron Content in TECu including heights from 80 $\mathrm{km}$ to HPL (plasma-pause height, typically $20200 \mathrm{~km}$ ).

Besides the empirical models, Global Positioning System (GPS) observations can be used to estimate GPS derived ionospheric TEC data (GPS_TEC). Because of the global coverage of the GPS, GPS_TEC is a good indicator of the geographical distribution of the ionization and proposed as an input for Ionosphere models [Misra and Enge 2006]. Since the GPS satellites are located at the altitude of $20200 \mathrm{~km}$, the amount of free electrons along the GPS ray path is composed mainly of Ionospheric Electron Content (IEC) and partly of Plasmaspheric Electron Content (PEC) [Balan et al. 2002, Cherniak et al. 2012, Karia et al. 2015, Akala et al. 2015].

Zakharenkova et al. [2015] compared TEC values, computed using IRI_2012 and IRI_PLAS models with GPS based TEC data, derived from European mid-latitude GPS station Potsdam. According to the results, comparative data model analysis does not reveal good performance. Arikan et al. [2015] examined the performance of IRI_PLAS map for the magnetically active day by comparing Global Ionosphere Map (GIMs). It is observed that the global distribution of TEC is very different due to the effect of geomagnetic disturbances.

Unlike other studies, this study examines the TEC prediction performance of IRI_PLAS model in different part of the world. This paper is divided into four sections. Following the introduction, the next section provides brief overview of the GPS_TEC, IRI_2012 and IRI_PLAS models. Then, a detailed presentation of the results derived from measurements and empirical models are given. Finally, the last section summarizes key conclusions.

\section{Material and Methods}

\subsection{Model Calculations}

\subsubsection{IRI_2012}

The International Reference Ionosphere (IRI) is an international project recommended by the Committee on Space Research (COSPAR) and the Inter- national Union of Radio Science (URSI) to provide ionospheric parameters. The first version of IRI was released in 1978 and several steadily improved editions followed since then (1986, 1990, 1995, 2001, 2007, 2012 and 2016) (URL-2, Alcay et al, 2014). Although the fortran source code of 2016 is available (URL-2), the web interface has not been published yet in the preparation of this study. Therefore IRI_2012 model was used in this study. The IRI_2012 was released in 2013 and includes several important improvements and additions which is given in Bilitza [2015] in detail. The IRI model provides many parameters, including Total Electron Content (TEC) electron density, ion and electron temperature, ion composition for a given latitude, longitude, time date at altitudes ranging from $60 \mathrm{~km}$ to 2000 $\mathrm{km}$. IRI based TEC data is derived by integrating the electron density profile from the lower boundary to the user specified upper boundary [Kumar et al. 2015]. In this study, in order to compute IRI_2012 TEC values, a web interface from the IRI homepage (URL-3) was used. Relevant to this study, NeQuick and ABT2009 options were used for topside electron density and bottomside thickness respectively. Since the CCIR option is recommended for continental areas and URSI option over the ocean areas [Aggarwal 2011], we used CCIR option for the F2 peak density calculations.

\subsubsection{IRI_PLAS}

Since the IRI model specifies the ionosphere only up to $2000 \mathrm{~km}$, increasing number of the researchers focused on the information about the plasma conditions above the ionosphere in the plasmasphere. The international reference ionosphere extended to the plasmasphere, IRI_PLAS, [Gulyaeva et al. 2002] has been proposed an empirical model where the region of interest includes the plasmasphere up to $20200 \mathrm{~km}$ [Gulyaeva et al. 2011]. A number of approaches have been proposed for extending IRI to the plasmasphere, including The Global Core Plasma Model (GCPM2000), The Global Plasmasphere Ionosphere Density (GPID), The IMAGE/RPI plasmasphere model and The IZMIRAN plasmasphere model. For the details of such models, authors refer to Gulyaeva and Bilitza [2012]. IONOLAB group presented a monitoring of space weather service that is available online at (URL1) [Arikan et al. 2015]. For a given date, time and location, this service provides many parameters, including IRI_PLAS TEC data. IONOLAB service provides IRI_PLAS data associated with the IZMIRAN plasmasphere model. IRI_PLAS source and executables are available at (URL-4). In this study, TEC values corre- 
sponding to IRI_PLAS model were estimated using IONOLAB service.

\subsection{GPS_TEC}

A dual frequency GPS receiver can provide code and phase observations. The geometry free linear combination of GPS signals (ionospheric observable) is classically used for ionospheric investigation which is generated by subtracting simultaneous pseudorange or carrier phase observations [Nohutcu et al. 2010]. Using such observations, slant TEC values are generated for each satellite and then they are converted VTEC values using single layer model and mapping function as explained in Arikan et al. [2003], Schaer [1999]. In this study, GPS TEC values over the IGS stations were estimated using ionolabtecv1.0, downloaded from the IONOLAB service. Using this program, STEC values are converted into VTEC values using the mapping function, provided in Arikan et al. [2003] and Nayir et al. [2007], for every position of the satellite with a 30 s time resolution. Then, in order to obtain an accurate and robust estimate of the TEC values in the zenith direction of the GPS receiver combining the computed VTEC data from all available satellites, Reg-Est (Regularized Estimation of TEC) algorithm is applied as discussed in Arikan et al. [2003, 2004] and Nayir et al. [2007].
As depicted in Figure 1, stations can be grouped into three latitude regions, including three stations each (WHIT-KIRU-TIXI, BARH-MADR-DAEJ, PARC-HRAO-YARR).

In addition, Table 1 illustrates the details of the stations including geographical coordinates, receiver and antenna information, etc.

Although the performance of IRI models is limited for the active days since they provide monthly average of the parameters, in order to determine the level of this deficiency, both active (18.03.2015, 20.12.2015, 21.12.2015) and quiet days (02.06.2015, 27.09.2015, 27.10.2015) were considered. Kp (URL-5) and Dst (URL-6) indice values are provided in Figures 2 and 3 respectively, to indicate the geomagnetic activity level.

On the quiet days, $\mathrm{Kp}$ indice values reach maximum 2 level (21-24 UT, 27.10.2015). Besides, Dst values are stable and highly low. However Kp indice values reach 6 level and above in some part of the active days, representing the disturbing ionospheric activity. Similar to the Kp values, Dst values are also relatively high (less than -150) for the morning hours (18.03.2015, 21.12.2015) and afternoon (20.12. 2015), refer to the severe activity level.

Diurnal variations of TEC data on the active and quiet days, obtained from GPS measurements and the empirical models over the 9 IGS stations, are

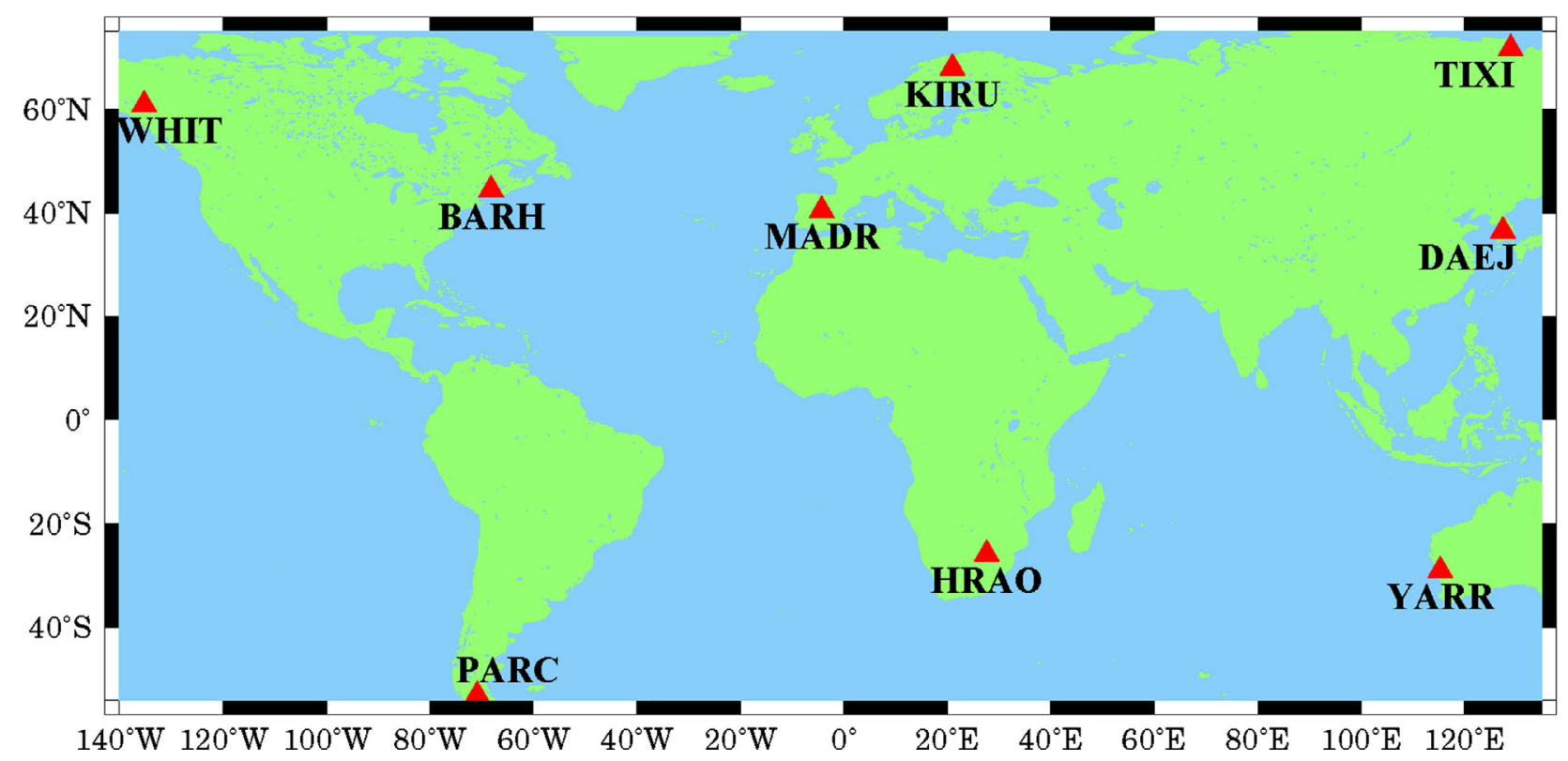

Figure 1. Location of the IGS stations used in the experiment.

\section{Results and Discussion}

The TEC values from the GPS, IRI_2012 and IRI_ PLAS models over the 9 IGS stations (Figure 1), located in different regions, were computed and compared. provided in Figures 4-12. Figures 4, 5 and 6 illustrate the TEC values over the northern hemisphere high latitude stations. Diurnal variations of the TEC values corresponding to GPS and empirical models ex- 


\begin{tabular}{|c|c|c|c|c|c|c|c|c|}
\hline STATION & NET. & COUNT. & LAT. & LON. & $\begin{array}{l}\text { HEIGHT } \\
(\mathbf{m})\end{array}$ & RECEIVER & ANTENNA & RADOME \\
\hline WHIT & IGS & Canada & 60.75 & -135.22 & 1427.00 & TPS NET-G3A & AOAD/M_T & NONE \\
\hline KIRU & IGS & Sweden & 67.86 & 20.97 & 391.10 & SEPT POLARX4 & $\begin{array}{c}\text { SEPCHOKE_ }_{\text {MC }} \\
\text { MC }\end{array}$ & SPKE \\
\hline TIXI & IGS & Russia & 71.63 & 128.87 & 46.98 & JPS EGGDT & TPSCR3_GGD & NONE \\
\hline BARH & IGS & $\mathrm{ABD}$ & 44.40 & -68.22 & 6.80 & $\begin{array}{c}\text { LEICA GR- } \\
\text { X1200GGPRO }\end{array}$ & LEIAX1202GG & NONE \\
\hline MADR & IGS & Spain & 40.43 & -4.25 & 829.50 & $\begin{array}{l}\text { JAVAD TRE_ } \\
\text { G3TH DELTA }\end{array}$ & AOAD/M_T & NONE \\
\hline DAEJ & IGS & S. Korea & 36.40 & 127.37 & 117.04 & TRIMBLE NETR9 & TRM59800.00 & SCIS \\
\hline PARC & IGS & Chile & -53.14 & -70.88 & 22.30 & TRIMBLE NETR8 & TRM57971.00 & NONE \\
\hline HRAO & IGS & S. Africa & -25.89 & 27.69 & 1414.30 & $\begin{array}{l}\text { JAVAD TRE_- } \\
\text { G3TH DELTA }\end{array}$ & ASH701945E_M & NONE \\
\hline YARR & IGS & Australia & -29.05 & 115.35 & 241.38 & $\begin{array}{l}\text { LEICA GR- } \\
\text { X1200+GNSS }\end{array}$ & LEIAT504 & NONE \\
\hline
\end{tabular}

Table 1. Details of the stations used in the experiment.

hibit similar behavior for the quiet days 27.09.2015 and 27.10.2015. In addition, IRI_PLAS TEC data are mostly closer to the GPS_TEC data comparing to the IRI_2012 TEC data, as expected. However for another quiet day (02.06.2015), GPS_TEC data
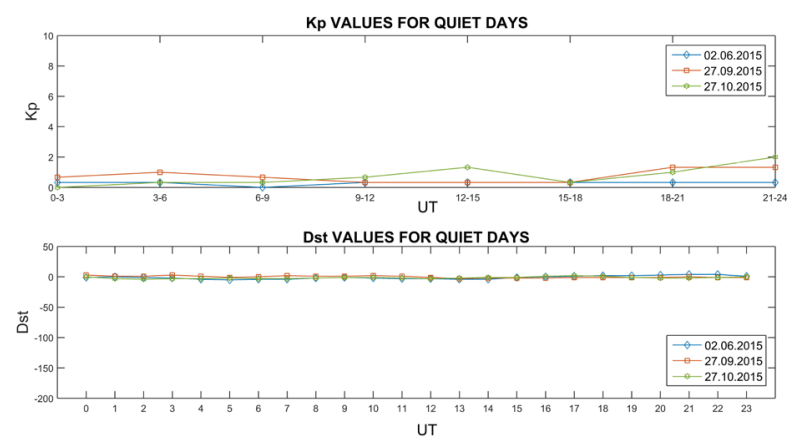

Figure 2. Kp and Dst indice values for the quiet days.
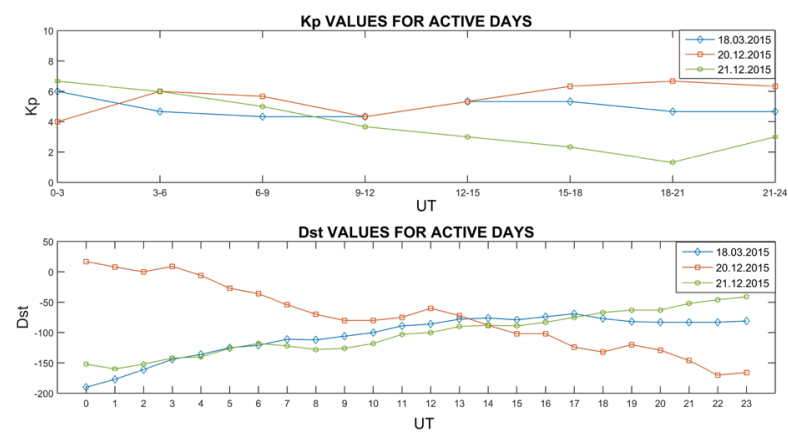

Figure 3. Kp and Dst indice values for the active day.

overestimate the model based data and maximum differences are 8.4 TECu level. On the active days, although differences between GPS_TEC and empirical models based TEC data are not at the high level, during 18.03.2015 and 20.12.2015, the IRI_2012 TEC

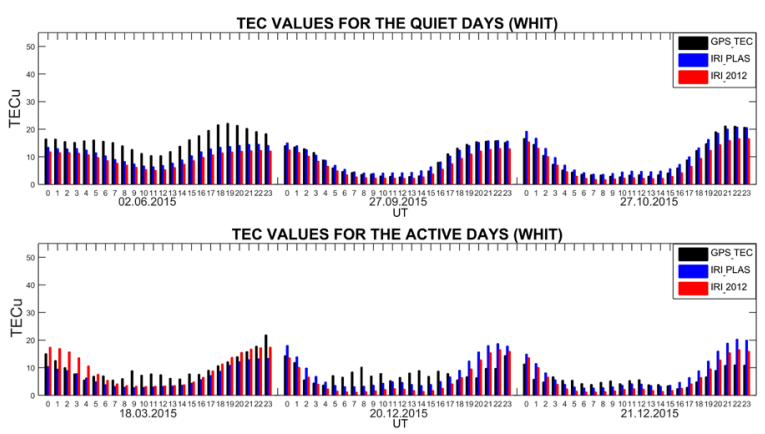

Figure 4. TEC comparison over the northern hemisphere high-latitude station WHIT.

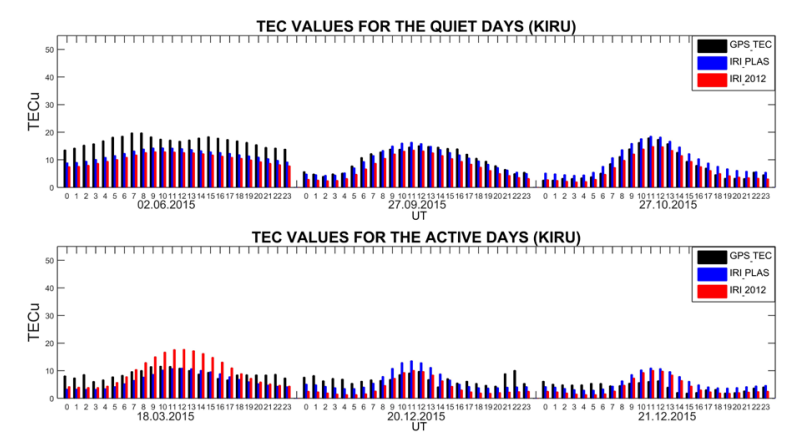

Figure 5. TEC comparison over the northern hemisphere high-latitude station KIRU.
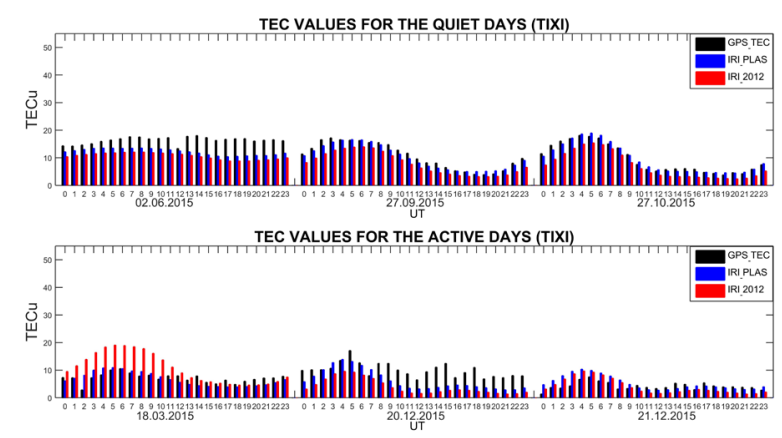

Figure 6. TEC comparison over the northern hemisphere high-latitude station TIXI. 
data and the GPS_TEC data generally reach highest level, respectively.

TEC values corresponding to northern hemisphere mid-latitude stations, BARH, MADR, DAEJ are provided in Figures 7, 8 and 9. During the quiet days, IRI_2012 TEC data are generally closer to the GPS_TEC data except 02.06.2015. Particularly during post-noon hours discrepancies between IRI_ PLAS TEC and GPS_TEC data reach largest level. On the active days, although GPS_TEC and models derived TEC data generally show similar trend for the particular hours, differences between them are at the high level. For instance, GPS_TEC data corresponding to BARH station on 20.12.2015 during 17-20 UT, reaching maximum 40 TECu level due to

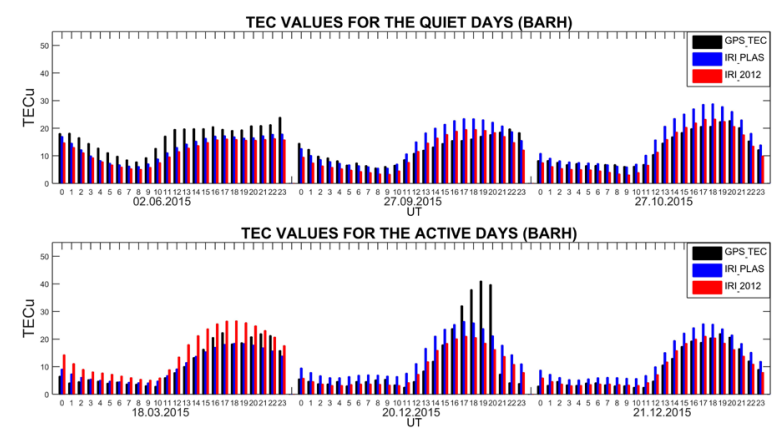

Figure 7. TEC comparison over the northern hemisphere mid-latitude station BARH.

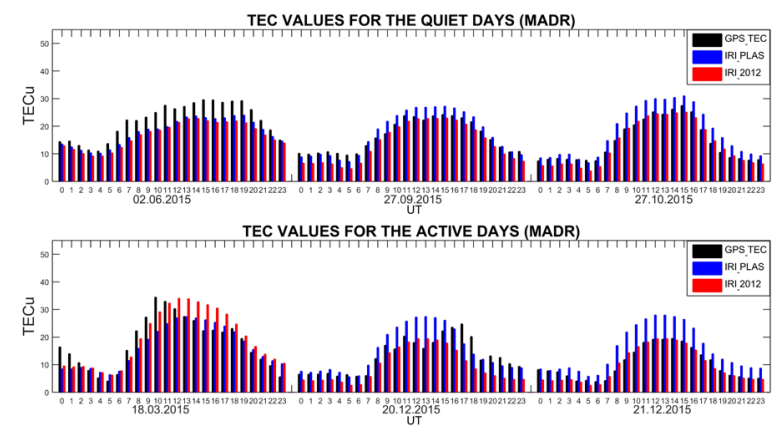

Figure 8. TEC comparison over the northern hemisphere mid-latitude station MADR.
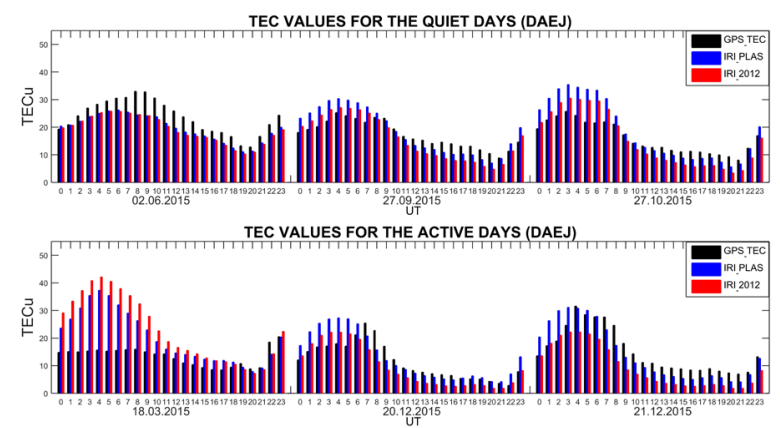

Figure 9. TEC comparison over the northern hemisphere mid-latitude station DAEJ. the increasing activity level as depicted in Kp values (Figure 3). However, while such influence can be observed slightly over MADR stations, any increase is not detected over DAEJ during this time period. Besides, although both GPS and empirical models derived TEC data exhibit similar trend over BARH and MADR on 18.03.2015, TEC differences corresponding to DAEJ station during post mid-night periods are very high. During such period, while GPS_TEC data are 15 TECu level, maximum values of IRI_2012 and IRI_PLAS TEC are 43 and 38 TECu respectively.

Similar to the northern hemisphere stations, TEC data corresponding to quiet days in the southern hemisphere high latitude stations (PARC, HRAO and YARR), exhibit similar behavior (Figures 10, 11 and

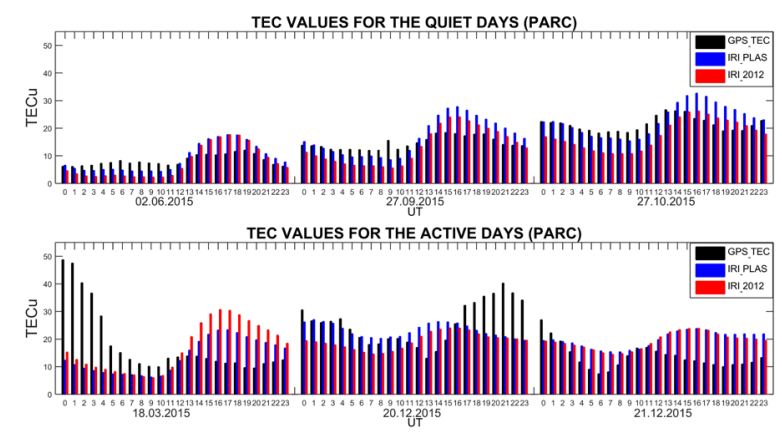

Figure 10. TEC comparison over the southern hemisphere high-latitude station PARC.

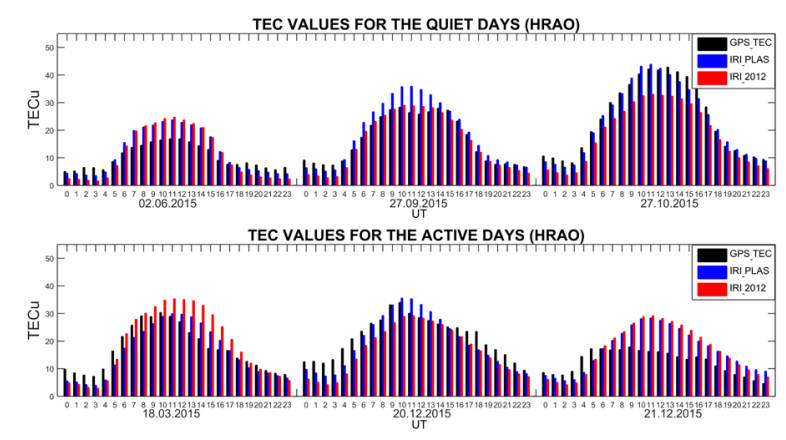

Figure 11. TEC comparison over the southern hemisphere high-latitude station HRAO.

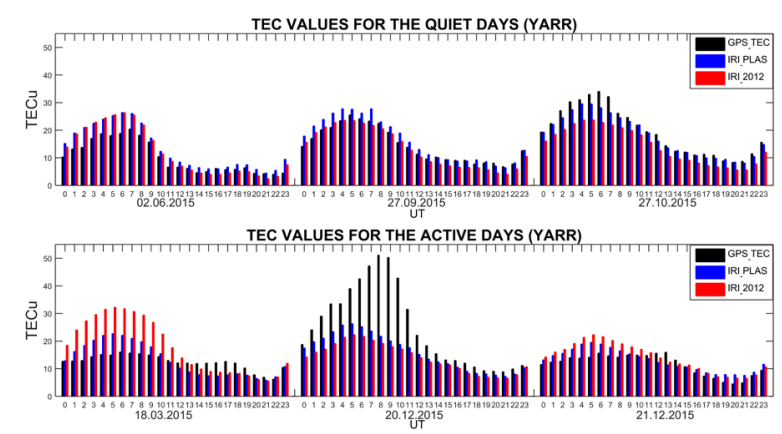

Figure 12. TEC comparison over the southern hemisphere high-latitude station YARR. 
ALCAY ET AL.

\begin{tabular}{|c|c|c|c|c|c|c|}
\hline \multicolumn{2}{|l|}{ WHIT } & \multicolumn{5}{|c|}{ Statistical Values (TECu) } \\
\hline$\Delta \mathrm{TEC}$ & Date & Maximum & Minimum & Range & Mean & Std \\
\hline \multirow[t]{6}{*}{ (GPS_TEC) - (IRI_PLAS) } & 02.06 .2015 & 8.4 & 2.2 & 6.2 & 5.0 & 1.6 \\
\hline & \multirow{2}{*}{$\begin{array}{l}27.09 .2015 \\
27.10 .2015\end{array}$} & 1.0 & -1.9 & 2.9 & -0.4 & 0.8 \\
\hline & & 1.1 & -2.6 & 3.7 & -1.1 & 1.0 \\
\hline & \multirow{3}{*}{$\begin{array}{l}18.03 .2015 \\
20.12 .2015 \\
21.12 .2015\end{array}$} & 8.5 & -0.8 & 9.3 & 3.0 & 1.9 \\
\hline & & 6.9 & -9.4 & 16.3 & -0.3 & 4.7 \\
\hline & & 2.4 & -9.3 & 11.8 & -1.9 & 3.8 \\
\hline \multirow[t]{6}{*}{ (GPS_TEC) - (IRI_2012) } & 02.06 .2015 & 10.4 & 3.9 & 6.6 & 6.7 & 1.8 \\
\hline & \multirow{2}{*}{$\begin{array}{l}27.09 .2015 \\
27.10 .2015\end{array}$} & 3.8 & 0.4 & 3.3 & 2.0 & 1.1 \\
\hline & & 5.3 & 0.3 & 4.9 & 1.9 & 1.4 \\
\hline & \multirow{3}{*}{$\begin{array}{l}18.03 .2015 \\
20.12 .2015 \\
21.12 .2015\end{array}$} & 5.6 & -5.8 & 11.4 & 0.4 & 3.3 \\
\hline & & 8.9 & -6.8 & 15.7 & 2.2 & 4.5 \\
\hline & & 3.9 & -5.5 & 9.5 & 0.2 & 3.2 \\
\hline \multirow[t]{6}{*}{ (IRI_PLAS) - (IRI_2012) } & 02.06 .2015 & 2.3 & 1.2 & 1.1 & 1.7 & 0.3 \\
\hline & \multirow{2}{*}{$\begin{array}{l}27.09 .2015 \\
27.10 .2015\end{array}$} & 3.1 & 1.7 & 1.4 & 2.4 & 0.5 \\
\hline & & 4.2 & 1.9 & 2.3 & 3.0 & 0.8 \\
\hline & & -0.2 & -7.5 & 7.3 & -2.6 & 2.3 \\
\hline & \multirow{2}{*}{$\begin{array}{l}20.12 .2015 \\
21.12 .2015\end{array}$} & 4.5 & 1.9 & 2.5 & 2.5 & 0.6 \\
\hline & & 4.1 & 1.3 & 2.8 & 2.1 & 0.8 \\
\hline
\end{tabular}

Table 2. Some statistical values corresponding to the differences of TEC values for WHIT.

\begin{tabular}{|c|c|c|c|c|c|c|}
\hline \multicolumn{2}{|l|}{ KIRU } & \multicolumn{5}{|c|}{ Statistical Values (TECu) } \\
\hline$\Delta \mathrm{TEC}$ & Date & Maximum & Minimum & Range & Mean & Std \\
\hline \multirow[t]{6}{*}{$($ GPS_TEC) $-($ IRI_PLAS $)$} & 02.06 .2015 & 6.6 & 2.7 & 4.0 & 4.9 & 1.1 \\
\hline & 27.09 .2015 & 2.2 & -2.2 & 4.4 & 0.3 & 1.0 \\
\hline & 27.10 .2015 & -0.1 & -3.5 & 3.3 & -1.9 & 0.9 \\
\hline & 18.03 .2015 & 5.4 & -1.7 & 7.1 & 2.1 & 2.0 \\
\hline & 20.12 .2015 & 6.0 & -4.7 & 10.7 & 0.5 & 3.1 \\
\hline & 21.12 .2015 & 2.4 & -5.9 & 8.3 & -1.4 & 2.6 \\
\hline \multirow{6}{*}{$($ GPS_TEC) - (IRI_2012) } & 02.06 .2015 & 8.1 & 4.1 & 3.9 & 6.3 & 1.1 \\
\hline & 27.09 .2015 & 4.5 & 0.7 & 3.8 & 2.6 & 0.9 \\
\hline & 27.10 .2015 & 3.1 & -0.9 & 4.1 & 1.0 & 1.1 \\
\hline & 18.03 .2015 & 4.7 & -7.4 & 12.2 & -0.9 & 4.1 \\
\hline & 20.12 .2015 & 7.7 & -2.2 & 9.9 & 2.9 & 2.7 \\
\hline & 21.12 .2015 & 4.1 & -4.4 & 8.5 & 0.3 & 2.8 \\
\hline \multirow{6}{*}{ (IRI_PLAS) - (IRI_2012) } & 02.06 .2015 & 1.7 & 1.1 & 0.7 & 1.4 & 0.1 \\
\hline & 27.09 .2015 & 2.9 & 1.8 & 1.1 & 2.3 & 0.3 \\
\hline & 27.10 .2015 & 3.8 & 2.3 & 1.5 & 2.9 & 0.5 \\
\hline & 18.03 .2015 & -0.2 & -6.9 & 6.6 & -3.1 & 2.5 \\
\hline & 20.12 .2015 & 3.6 & 1.7 & 1.9 & 2.5 & 0.6 \\
\hline & 21.12 .2015 & 2.2 & 0.9 & 1.3 & 1.6 & 0.3 \\
\hline
\end{tabular}

Table 3. Some statistical values corresponding to the differences of TEC values for KIRU.

12). Moreover, while IRI_PLAS TEC data are generally consistent to the GPS TEC data on 27.10.2015 for PARC and HRAO stations, IRI_2012 TEC data are closer to the GPS_TEC data on 27.09.2015 for DAEJ and HRAO stations. Meanwhile except the northern hemisphere stations, the effect of the activity is apparent clearly in terms of TEC increase over the southern hemisphere stations. GPS_TEC data overestimate the models based TEC data on
18.03.2015 during post-midnight period over PARC stations and on 20.12.2015 over PARC and YARR stations during post-sunset and post-midnight period, respectively.

Since the days of equinoxes 18.03.2015 and 27.09.2015 refer to the equivalent conditions at all stations, similar trend is observed. However, due to the influence of the geomagnetic conditions, GPS TEC values show sudden increase and decrease, 


\begin{tabular}{|c|c|c|c|c|c|c|}
\hline \multicolumn{2}{|l|}{ TIXI } & \multicolumn{5}{|c|}{ Statistical Values (TECu) } \\
\hline$\triangle \mathrm{TEC}$ & Date & Maximum & Minimum & Range & Mean & Std \\
\hline \multirow[t]{6}{*}{ (GPS_TEC) - (IRI_PLAS) } & 02.06 .2015 & 6.4 & 0.9 & 5.5 & 4.2 & 1.7 \\
\hline & 27.09 .2015 & 2.2 & -1.3 & 3.4 & 0.6 & 1.0 \\
\hline & 27.10 .2015 & 1.7 & -1.2 & 2.8 & 0.0 & 0.8 \\
\hline & 18.03 .2015 & 3.5 & -5.3 & 8.8 & 0.4 & 2.0 \\
\hline & 20.12 .2015 & 8.1 & -2.3 & 10.4 & 3.7 & 2.7 \\
\hline & 21.12 .2015 & 1.9 & -5.3 & 7.2 & -1.0 & 2.0 \\
\hline \multirow[t]{6}{*}{ (GPS_TEC) - (IRI_2012) } & 02.06 .2015 & 8.0 & 2.1 & 6.0 & 5.7 & 1.7 \\
\hline & 27.09 .2015 & 5.1 & 0.7 & 4.4 & 2.8 & 1.1 \\
\hline & 27.10 .2015 & 5.1 & 1.3 & 3.8 & 2.6 & 1.0 \\
\hline & 18.03 .2015 & 2.2 & -11.1 & 13.2 & -3.5 & 4.7 \\
\hline & 20.12 .2015 & 9.7 & 1.0 & 8.8 & 6.1 & 2.1 \\
\hline & 21.12 .2015 & 3.1 & -4.4 & 7.5 & 0.2 & 2.2 \\
\hline \multirow[t]{6}{*}{ (IRI_PLAS) - (IRI_2012) } & 02.06 .2015 & 1.9 & 1.2 & 0.7 & 1.5 & 0.2 \\
\hline & 27.09 .2015 & 3.0 & 1.6 & 1.4 & 2.2 & 0.4 \\
\hline & 27.10 .2015 & 3.7 & 1.9 & 1.8 & 2.6 & 0.6 \\
\hline & 18.03 .2015 & -0.3 & -8.8 & 8.5 & -3.9 & 3.0 \\
\hline & 20.12 .2015 & 4.3 & 1.4 & 2.9 & 2.4 & 0.9 \\
\hline & 21.12 .2015 & 1.9 & 0.6 & 1.2 & 1.3 & 0.3 \\
\hline
\end{tabular}

Table 4. Some statistical values corresponding to the differences of TEC values for TIXI.

\begin{tabular}{|c|c|c|c|c|c|c|}
\hline \multicolumn{2}{|l|}{ BARH } & \multicolumn{5}{|c|}{ Statistical Values (TECu) } \\
\hline$\triangle \mathrm{TEC}$ & Date & Maximum & Minimum & Range & Mean & Std \\
\hline \multirow[t]{6}{*}{ (GPS_TEC) -(IRI_PLAS) } & 02.06 .2015 & 6.6 & 1.1 & 5.5 & 3.7 & 1.4 \\
\hline & 27.09 .2015 & 2.8 & -7.9 & 10.8 & -2.0 & 3.6 \\
\hline & 27.10 .2015 & 0.6 & -8.2 & 8.8 & -3.1 & 2.8 \\
\hline & 18.03 .2015 & 5.6 & -3.3 & 8.9 & 0.3 & 2.3 \\
\hline & 20.12 .2015 & 18.5 & -10.5 & 29.0 & -1.6 & 7.5 \\
\hline & 21.12 .2015 & -0.8 & -6.7 & 5.9 & -3.4 & 1.6 \\
\hline \multirow[t]{6}{*}{ (GPS_TEC) - (IRI_2012) } & 02.06 .2015 & 8.1 & 2.7 & 5.4 & 5.0 & 1.5 \\
\hline & 27.09 .2015 & 6.3 & -4.0 & 10.3 & 1.0 & 3.1 \\
\hline & 27.10 .2015 & 3.4 & -2.6 & 6.0 & 0.8 & 1.9 \\
\hline & 18.03 .2015 & 0.6 & -8.4 & 8.9 & -4.3 & 2.5 \\
\hline & 20.12 .2015 & 23.5 & -6.7 & 30.2 & 2.3 & 8.0 \\
\hline & 21.12 .2015 & 4.5 & -2.9 & 7.4 & -0.1 & 1.8 \\
\hline \multirow[t]{6}{*}{ (IRI_PLAS) - (IRI_2012) } & 02.06 .2015 & 2.3 & 0.5 & 1.8 & 1.3 & 0.4 \\
\hline & 27.09 .2015 & 4.0 & 1.9 & 2.1 & 3.1 & 0.8 \\
\hline & 27.10 .2015 & 5.6 & 2.5 & 3.0 & 4.0 & 1.1 \\
\hline & 18.03 .2015 & -1.0 & -8.5 & 7.5 & -4.6 & 2.6 \\
\hline & 20.12 .2015 & 5.4 & 2.8 & 2.6 & 3.9 & 0.9 \\
\hline & 21.12 .2015 & 5.3 & 2.0 & 3.3 & 3.3 & 1.0 \\
\hline
\end{tabular}

Table 5. Some statistical values corresponding to the differences of TEC values for BARH.

comparing to the model based TEC data. Therefore, only the quiet day (27.09.2015) can allow to analyze the latitudinal characteristics of the results. During this day, TEC values corresponding to GPS_TEC and model based TEC of northern hemisphere high latitude stations are highly consistent in terms of both TEC values and trend. Similar condition is derived at one of the southern hemisphere high latitude station (YARR), located at the eastern part of the region (Figure 12). However, at other southern hemisphere stations (PARC, HRAO), while all three results show similar trend, differences between
GPS_TEC and IRI_PLAS TEC are above 8 TECu in some part of the day. In addition, particularly for the HRAO, IRI_2012 results are mostly close to the GPS_TEC data. Comparing to the PARC and HRAO, differences of mid-latitude stations are at lower level.

Days 20.12.2015 and 21.12.2015 refer to the same magnetic storm with the 1st day (20.12.2015) during the main phase of the storm and the 2 nd day (21.12.2015) at the recovering phase of the storm. The influence of the storm on 20.12.2015 is apparent at all stations however at different level. Particularly, 
ALCAY ET AL.

\begin{tabular}{|c|c|c|c|c|c|c|}
\hline \multicolumn{2}{|l|}{ MADR } & \multicolumn{5}{|c|}{ Statistical Values (TECu) } \\
\hline$\Delta \mathrm{TEC}$ & Date & Maximum & Minimum & Range & Mean & Std \\
\hline \multirow[t]{6}{*}{ (GPS_TEC) $-($ IRI_PLAS) } & 02.06 .2015 & 7.7 & 0.4 & 7.4 & 4.0 & 2.1 \\
\hline & 27.09 .2015 & 2.5 & -4.7 & 7.1 & -1.2 & 2.1 \\
\hline & 27.10 .2015 & 0.9 & -6.8 & 7.7 & -3.5 & 2.2 \\
\hline & 18.03 .2015 & 12.4 & -4.7 & 17.1 & 1.4 & 4.4 \\
\hline & 20.12 .2015 & 7.2 & -11.5 & 18.7 & -1.8 & 4.5 \\
\hline & 21.12 .2015 & -0.2 & -10.0 & 9.8 & -5.1 & 3.1 \\
\hline \multirow[t]{6}{*}{ (GPS_TEC) - (IRI_2012) } & 02.06 .2015 & 8.1 & 1.1 & 7.0 & 5.1 & 2.2 \\
\hline & 27.09 .2015 & 5.2 & -0.6 & 5.8 & 2.3 & 1.5 \\
\hline & 27.10 .2015 & 3.9 & -1.3 & 5.2 & 0.8 & 1.4 \\
\hline & 18.03 .2015 & 6.9 & -9.4 & 16.3 & -1.4 & 4.2 \\
\hline & 20.12 .2015 & 13.3 & -3.5 & 16.8 & 3.6 & 3.9 \\
\hline & 21.12 .2015 & 3.7 & -2.8 & 6.5 & 0.6 & 1.7 \\
\hline \multirow[t]{6}{*}{ (IRI_PLAS) - (IRI_2012) } & 02.06 .2015 & 2.8 & 0.2 & 2.6 & 1.2 & 0.6 \\
\hline & 27.09 .2015 & 4.7 & 2.4 & 2.4 & 3.5 & 0.8 \\
\hline & 27.10 .2015 & 5.9 & 2.8 & 3.1 & 4.3 & 1.1 \\
\hline & 18.03 .2015 & 0.2 & -7.5 & 7.6 & -2.9 & 2.7 \\
\hline & 20.12 .2015 & 8.3 & 3.0 & 5.3 & 5.3 & 1.9 \\
\hline & 21.12 .2015 & 8.6 & 3.3 & 5.3 & 5.7 & 1.9 \\
\hline
\end{tabular}

Table 6. Some statistical values corresponding to the differences of TEC values for MADR.

\begin{tabular}{|c|c|c|c|c|c|c|}
\hline \multicolumn{2}{|l|}{ DAEJ } & \multicolumn{5}{|c|}{ Statistical Values (TECu) } \\
\hline$\triangle \mathrm{TEC}$ & Date & Maximum & Minimum & Range & Mean & Std \\
\hline \multirow[t]{6}{*}{$($ GPS_TEC) $-($ IRI_PLAS $)$} & 02.06 .2015 & 8.7 & -1.1 & 9.8 & 3.9 & 2.3 \\
\hline & 27.09 .2015 & 3.8 & -7.5 & 11.3 & -1.1 & 4.0 \\
\hline & 27.10 .2015 & 3.7 & -11.9 & 15.6 & -2.5 & 5.3 \\
\hline & 18.03 .2015 & 4.4 & -21.7 & 26.1 & -6.9 & 7.4 \\
\hline & 20.12 .2015 & 7.0 & -9.9 & 17.0 & -1.6 & 4.8 \\
\hline & 21.12 .2015 & 7.2 & -11.0 & 18.2 & 0.8 & 4.5 \\
\hline \multirow[t]{6}{*}{$($ GPS_TEC) $-($ IRI_201)2 } & 02.06 .2015 & 8.6 & -0.5 & 9.1 & 4.4 & 2.4 \\
\hline & 27.09 .2015 & 6.1 & -4.2 & 10.3 & 1.4 & 3.8 \\
\hline & 27.10 .2015 & 5.9 & -7.9 & 13.9 & 0.8 & 4.5 \\
\hline & 18.03 .2015 & 4.2 & -26.5 & 30.7 & -9.7 & 9.8 \\
\hline & 20.12 .2015 & 11.3 & -5.0 & 16.4 & 2.0 & 4.3 \\
\hline & 21.12 .2015 & 13.1 & -2.1 & 15.2 & 5.8 & 3.4 \\
\hline \multirow[t]{6}{*}{ (IRI_PLAS) - (IRI_2012) } & 02.06 .2015 & 1.5 & -0.3 & 1.8 & 0.5 & 0.5 \\
\hline & 27.09 .2015 & 3.3 & 2.0 & 1.3 & 2.5 & 0.4 \\
\hline & 27.10 .2015 & 5.0 & 2.2 & 2.8 & 3.3 & 0.9 \\
\hline & 18.03 .2015 & 0.8 & -6.5 & 7.4 & -2.8 & 2.7 \\
\hline & 20.12 .2015 & 5.6 & 2.4 & 3.2 & 3.6 & 1.1 \\
\hline & 21.12 .2015 & 8.9 & 2.3 & 6.6 & 5.0 & 2.4 \\
\hline
\end{tabular}

Table 7. Some statistical values corresponding to the differences of TEC values for DAEJ.

the influences of the storm are observed just after midnight hours (0 UT - 3 UT) and after 12 UT. Such condition is more clear at GPS_TEC data corresponding to BARH and PARC after 15 UT and YARR during morning hours. In addition, during the recovering phase of the storm (21.12.2015), the influence of the storm on TEC values are not clear except PARC and HRAO. Particularly, influence of the increasing level of the storm after 12 UT on 20.12.2015 and its decreasing level during 0 UT - 3 UT on 21.12.2015 is observed clearly at PARC station (Figure 10).

In addition, one of the quiet days (02.06.2015) refers to summer conditions in the northern hemisphere and winter conditions in the southern hemisphere. It is interesting to note that GPS_TEC data overestimate the model based data at all northern hemisphere stations. Particularly in some part of the WHIT, differences are above 8 TECu. However GPS_TEC data is below the models based data at the southern hemisphere stations. Such results prove the significant effect of the seasonal conditions on TEC data which is not able to reflected properly by the models.

In order to facilitate the comparison and obtain 


\begin{tabular}{|c|c|c|c|c|c|c|}
\hline \multicolumn{2}{|l|}{ PARC } & \multicolumn{5}{|c|}{ Statistical Values (TECu) } \\
\hline$\triangle \mathrm{TEC}$ & Date & Maximum & Minimum & Range & Mean & Std \\
\hline \multirow[t]{6}{*}{ (GPS_TEC) - (IRI_PLAS) } & 02.06 .2015 & 3.4 & -6.9 & 10.4 & -0.8 & 3.3 \\
\hline & 27.09 .2015 & 6.9 & -9.7 & 16.7 & -2.0 & 4.5 \\
\hline & 27.10 .2015 & 3.6 & -9.2 & 12.8 & -1.5 & 4.4 \\
\hline & 18.03 .2015 & 36.8 & -12.1 & 48.9 & 4.3 & 15.1 \\
\hline & 20.12 .2015 & 19.4 & -12.8 & 32.1 & 2.5 & 8.5 \\
\hline & 21.12 .2015 & 7.5 & -12.0 & 19.6 & -6.2 & 5.2 \\
\hline \multirow[t]{6}{*}{ (GPS_TEC) - (IRI_2012) } & 02.06 .2015 & 5.6 & -7.0 & 12.5 & 0.7 & 4.1 \\
\hline & 27.09 .2015 & 10.0 & -6.0 & 16.0 & 1.3 & 4.5 \\
\hline & 27.10 .2015 & 8.1 & -3.9 & 12.0 & 3.8 & 4.2 \\
\hline & 18.03 .2015 & 34.9 & -19.2 & 54.1 & 1.2 & 16.8 \\
\hline & 20.12 .2015 & 19.9 & -9.8 & 29.6 & 6.3 & 7.6 \\
\hline & 21.12 .2015 & 7.7 & -11.9 & 19.5 & -5.7 & 5.0 \\
\hline \multirow[t]{6}{*}{ (IRI_PLAS) - (IRI_2012) } & 02.06 .2015 & 2.3 & 0.0 & 2.3 & 1.5 & 0.8 \\
\hline & 27.09 .2015 & 4.0 & 2.8 & 1.2 & 3.3 & 0.3 \\
\hline & 27.10 .2015 & 6.5 & 4.1 & 2.4 & 5.3 & 0.7 \\
\hline & 18.03 .2015 & 0.3 & -7.5 & 7.8 & -3.1 & 2.6 \\
\hline & 20.12 .2015 & 8.0 & -0.1 & 8.1 & 3.8 & 2.6 \\
\hline & 21.12 .2015 & 2.4 & -1.0 & 3.4 & 0.5 & 0.8 \\
\hline
\end{tabular}

Table 8. Some statistical values corresponding to the differences of TEC values for PARC.

\begin{tabular}{|c|c|c|c|c|c|c|}
\hline \multicolumn{2}{|l|}{ HRAO } & \multicolumn{5}{|c|}{ Statistical Values (TECu) } \\
\hline$\triangle \mathrm{TEC}$ & Date & Maximum & Minimum & Range & Mean & Std \\
\hline \multirow[t]{6}{*}{ (GPS_TEC) - (IRI_PLAS) } & 02.06 .2015 & 2.9 & -6.9 & 9.8 & -1.9 & 3.7 \\
\hline & 27.09 .2015 & 2.8 & -9.6 & 12.4 & -2.4 & 3.5 \\
\hline & 27.10 .2015 & 4.6 & -2.8 & 7.4 & 0.8 & 2.0 \\
\hline & 18.03 .2015 & 5.6 & -6.0 & 11.7 & 1.1 & 3.4 \\
\hline & 20.12 .2015 & 6.6 & -5.3 & 11.9 & 1.8 & 3.4 \\
\hline & 21.12 .2015 & 5.8 & -12.1 & 17.9 & -4.3 & 5.1 \\
\hline \multirow[t]{6}{*}{ (GPS_TEC) - (IRI_2012) } & 02.06 .2015 & 4.8 & -7.9 & 12.7 & -1.0 & 4.8 \\
\hline & 27.09 .2015 & 5.3 & -2.8 & 8.1 & 1.1 & 2.3 \\
\hline & 27.10 .2015 & 10.6 & 1.8 & 8.8 & 5.8 & 2.7 \\
\hline & 18.03 .2015 & 5.0 & -12.2 & 17.2 & -1.9 & 5.4 \\
\hline & 20.12 .2015 & 9.2 & 0.2 & 9.1 & 4.7 & 2.6 \\
\hline & 21.12 .2015 & 6.4 & -12.9 & 19.3 & -4.2 & 5.8 \\
\hline \multirow[t]{6}{*}{ (IRI_PLAS) - (IRI_2012) } & 02.06 .2015 & 2.3 & -1.0 & 3.3 & 0.9 & 1.2 \\
\hline & 27.09 .2015 & 7.1 & 2.0 & 5.1 & 3.5 & 1.5 \\
\hline & 27.10 .2015 & 10.9 & 2.7 & 8.2 & 5.0 & 2.6 \\
\hline & 18.03 .2015 & 1.0 & -6.7 & 7.7 & -3.0 & 2.9 \\
\hline & 20.12 .2015 & 6.7 & -0.4 & 7.1 & 2.8 & 2.1 \\
\hline & 21.12 .2015 & 2.1 & -1.7 & 3.8 & 0.1 & 1.1 \\
\hline
\end{tabular}

Table 9. Some statistical values corresponding to the differences of TEC values for HRAO.

more quantitative estimation, some statistical values corresponding to differences between GPS_TEC and empirical models and also between empirical models, including minimum, maximum, range, mean and Std values are provided in Tables 2-10. According to the values given in tables, the superiority of the IRI_PLAS model is not apparent, comparing to the IRI_2012 model for the quiet days. For some quiet days and stations, while IRI_PLAS TEC data are closer to the GPS_TEC data, for others IRI_2012 TEC data show good agreement with GPS_TEC data. On the active days, although maximum differ- ences between GPS_TEC and empirical models are generally less than $10 \mathrm{TECu}$, they reach high values in some time periods due to the increase of the TEC data caused by the geomagnetic activity observed from the GPS measurements (Tables 5, 8 and 10). The most intense difference is observed between GPS_TEC and empirical models TEC on 18.03.2015 for PARC station located at southern hemisphere high latitude.

In order to further examine the consistency and find out how the TEC estimated from empirical models are correlated with GPS_TEC, the correla- 
ALCAY ET AL.

\begin{tabular}{|c|c|c|c|c|c|c|}
\hline \multicolumn{2}{|l|}{ YARR } & \multicolumn{5}{|c|}{ Statistical Values (TECu) } \\
\hline$\triangle \mathrm{TEC}$ & Date & Maximum & Minimum & Range & Mean & Std \\
\hline \multirow[t]{6}{*}{ (GPS_TEC) - (IRI_PLAS) } & 02.06 .2015 & 0.2 & -7.6 & 7.8 & -3.2 & 2.4 \\
\hline & 27.09 .2015 & 1.1 & -5.2 & 6.3 & -1.7 & 1.8 \\
\hline & 27.10 .2015 & 5.9 & -0.5 & 6.4 & 1.4 & 1.7 \\
\hline & 18.03 .2015 & 4.9 & -7.8 & 12.7 & -0.7 & 4.0 \\
\hline & 20.12 .2015 & 30.2 & 0.8 & 29.3 & 8.9 & 9.2 \\
\hline & 21.12 .2015 & 4.6 & -5.4 & 10.0 & -1.4 & 2.4 \\
\hline \multirow[t]{6}{*}{ (GPS_TEC) - (IRI_2012) } & 02.06 .2015 & 2.2 & -7.6 & 9.8 & -2.0 & 3.2 \\
\hline & 27.09 .2015 & 3.6 & -2.2 & 5.8 & 1.1 & 1.5 \\
\hline & 27.10 .2015 & 11.2 & 2.7 & 8.6 & 5.0 & 2.5 \\
\hline & 18.03 .2015 & 4.0 & -17.3 & 21.3 & -5.5 & 7.7 \\
\hline & 20.12 .2015 & 32.3 & 0.5 & 31.8 & 10.9 & 9.9 \\
\hline & 21.12 .2015 & 3.6 & -8.2 & 11.7 & -2.4 & 2.8 \\
\hline \multirow[t]{6}{*}{ (IRI_PLAS) - (IRI_2012) } & 02.06 .2015 & 2.5 & -0.5 & 3.0 & 1.2 & 1.0 \\
\hline & 27.09 .2015 & 6.1 & 2.2 & 3.9 & 2.9 & 0.9 \\
\hline & 27.10 .2015 & 5.8 & 2.5 & 3.3 & 3.6 & 1.0 \\
\hline & 18.03 .2015 & 0.4 & -9.7 & 10.1 & -4.7 & 3.9 \\
\hline & 20.12 .2015 & 4.4 & -0.4 & 4.8 & 2.0 & 1.4 \\
\hline & 21.12 .2015 & 1.3 & -2.8 & 4.0 & -1.0 & 1.4 \\
\hline
\end{tabular}

Table 10. Some statistical values corresponding to the differences of TEC values for YARR.

tion coefficients between such data sets were computed using the following equations:

Correl. Coeff. ${\cdot\left(G P S-I R I_{-} P L A S\right)}=\frac{\sum_{i}\left(G P S_{i}-\overline{G P S_{i}}\right)\left(I R I_{-} P L A S_{i}-\overline{I R I_{-} P L A S_{i}}\right)}{\sqrt{\sum_{i}\left(G P S_{i}-\overline{G P S_{i}}\right)^{2}\left(I R I_{-} P L A S_{i}-\overline{I_{1} I_{-} P L A S_{i}}\right)^{2}}}$

Correl. Coeff $\cdot_{\left(G P S-I R I \_2012\right)}=\frac{\sum_{i}\left(G P S_{i}-\overline{G P S_{i}}\right)\left(I R I_{-} 2012_{i}-\overline{I R I_{-} 2012_{i}}\right)}{\sqrt{\left.\sum_{i}\left(G P S_{i}-\overline{G P S}\right)_{i}\right)^{2}\left(I R I_{-} 2012_{i}-\overline{I_{1} I_{-} 2012_{i}}\right)^{2}}}$

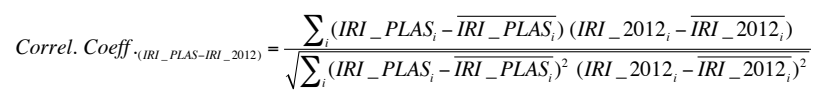

Where GPS $_{i}$ is respective GPS_TEC data, $\overline{G P S}_{i}$ is their mean, IRI_2012 $2_{i}$ and IRI_PLAS $S_{i}$ are respective IRI_2012 and IRI_PLAS TEC data, $\left(\overline{I R I \_2012}_{i}\right)$ and $\overline{I R I \_P L A S}_{i}$ are their mean values. Subscripts "i” denotes numerical position in the data. The correlation coefficients between GPS_TEC data and empirical models derived TEC data are depicted in Table 11. It is noticed that the correlation coefficients between GPS_TEC and empirical models exhibit high agreement which are generally above 0.90 for the quiet days at all station except TIXI. Although correlation coefficients are above 0.97 for TIXI on 27.09.2015 and 27.10.2015, there is no correlation between such data sets on 02.06.2015. Although TEC differences between GPS_TEC and empirical models are not at the large level, less than $8 \mathrm{TECu}$, the reason of such correlation is due to the trends of data sets which are not consistent (Figure 6). While GPS_TEC data have decreasing trend during post noon hours, models derived TEC data have decreasing trend until 17 UT and then they have increasing trend. As expected, correlation coefficients between GPS_TEC and empirical models derived TEC data for the active days are at different level due to the activity level and its effects on TEC values which are detected by GPS based observations. On the other hand, there are good correlation coefficients between IRI_PLAS and IRI_2012 models, about 0.99 level, at all stations for both geomagnetic conditions.

\section{Conclusion}

In the present study, we compared TEC values from GPS measurements with corresponding TEC data from the IRI_PLAS and IRI_2012 models over the 9 IGS stations, located three different latitude regions. Comparison was applied for three geomagnetic active and quiet days. Although the drawbacks of empirical models are well known for the active days since they give monthly average values, in order to determine the magnitude of the differences, active days were considered in this study. According to the results, while maximum differences between GPS TEC and empirical models based TEC data are gen- 


\begin{tabular}{|c|c|c|c|c|c|c|c|}
\hline \multirow[t]{2}{*}{ Stations } & \multirow[t]{2}{*}{ Corr. Coeff. Between } & \multicolumn{3}{|c|}{ Quiet Days } & \multicolumn{3}{|c|}{ Active Days } \\
\hline & & 02.06 .2015 & 27.09 .2015 & 27.10 .2015 & 18.03.2015 & 20.12 .2015 & 21.12 .2015 \\
\hline \multirow[t]{3}{*}{ WHIT } & GPS_TEC and IRI_PLAS & 0.8845 & 0.9910 & 0.9900 & 0.8910 & 0.5378 & 0.8813 \\
\hline & GPS_TEC and IRI_2012 & 0.8602 & 0.9894 & 0.9885 & 0.8117 & 0.5405 & 0.8924 \\
\hline & IRI_PLAS and IRI_2012 & 0.9963 & 0.9983 & 0.9988 & 0.9570 & 0.9953 & 0.9959 \\
\hline \multirow[t]{3}{*}{ KIRU } & GPS_TEC and IRI_PLAS & 0.8137 & 0.9693 & 0.9867 & 0.6914 & 0.3997 & 0.2888 \\
\hline & GPS_TEC and IRI_2012 & 0.8209 & 0.9710 & 0.9867 & 0.7340 & 0.3932 & 0.3233 \\
\hline & IRI_PLAS and IRI_2012 & 0.9979 & 0.9987 & 0.9987 & 0.9870 & 0.9938 & 0.9981 \\
\hline \multirow[t]{3}{*}{ TIXI } & GPS_TEC and IRI_PLAS & -0.1013 & 0.9773 & 0.9890 & 0.5754 & 0.6595 & 0.5531 \\
\hline & GPS_TEC and IRI_2012 & -0.0252 & 0.9779 & 0.9847 & 0.5540 & 0.6648 & 0.5802 \\
\hline & IRI_PLAS and IRI_2012 & 0.9832 & 0.9981 & 0.9985 & 0.9806 & 0.9985 & 0.9963 \\
\hline \multirow[t]{3}{*}{ BARH } & GPS_TEC and IRI_PLAS & 0.9547 & 0.8693 & 0.9795 & 0.9711 & 0.8392 & 0.9764 \\
\hline & GPS_TEC and IRI_2012 & 0.9491 & 0.8639 & 0.9779 & 0.9485 & 0.8358 & 0.9674 \\
\hline & IRI_PLAS and IRI_2012 & 0.9959 & 0.9994 & 0.9994 & 0.9921 & 0.9993 & 0.9980 \\
\hline \multirow[t]{3}{*}{ MADR } & GPS_TEC and IRI_PLAS & 0.9750 & 0.9884 & 0.9821 & 0.8717 & 0.8164 & 0.9570 \\
\hline & GPS_TEC and IRI_2012 & 0.9721 & 0.9721 & 0.9838 & 0.9071 & 0.7970 & 0.9600 \\
\hline & IRI_PLAS and IRI_2012 & 0.9919 & 0.9992 & 0.9995 & 0.9942 & 0.9988 & 0.9997 \\
\hline \multirow[t]{3}{*}{ DAEJ } & GPS_TEC and IRI_PLAS & 0.9313 & 0.9202 & 0.9836 & 0.6625 & 0.8255 & 0.8973 \\
\hline & GPS_TEC and IRI_2012 & 0.9162 & 0.9269 & 0.9827 & 0.6750 & 0.8190 & 0.9007 \\
\hline & IRI_PLAS and IRI_2012 & 0.9962 & 0.9993 & 0.9992 & 0.9946 & 0.9985 & 0.9998 \\
\hline \multirow[t]{3}{*}{ PARC } & GPS_TEC and IRI_PLAS & 0.8939 & 0.9024 & 0.6064 & -0.3233 & -0.2314 & 0.0229 \\
\hline & GPS_TEC and IRI_2012 & 0.8980 & 0.9076 & 0.6032 & -0.3032 & 0.1914 & 0.0919 \\
\hline & IRI_PLAS and IRI_2012 & 0.9997 & 0.9986 & 0.9912 & 0.9961 & 0.5437 & 0.9608 \\
\hline \multirow[t]{3}{*}{ HRAO } & GPS_TEC and IRI_PLAS & 0.9875 & 0.9757 & 0.9883 & 0.9313 & 0.9649 & 0.7669 \\
\hline & GPS_TEC and IRI_2012 & 0.9868 & 0.9793 & 0.9918 & 0.9371 & 0.9602 & 0.7968 \\
\hline & IRI_PLAS and IRI_2012 & 0.9993 & 0.9975 & 0.9951 & 0.9965 & 0.9806 & 0.9973 \\
\hline \multirow[t]{3}{*}{ YARR } & GPS_TEC and IRI_PLAS & 0.9792 & 0.9840 & 0.9882 & 0.8123 & 0.8746 & 0.7997 \\
\hline & GPS_TEC and IRI_2012 & 0.9773 & 0.9803 & 0.9824 & 0.8304 & 0.8988 & 0.8494 \\
\hline & IRI_PLAS and IRI_2012 & 0.9990 & 0.9957 & 0.9975 & 0.9950 & 0.9918 & 0.9927 \\
\hline
\end{tabular}

Table 11. Correlation coefficients between GPS_TEC and empirical models based TEC values.

erally less than 10 TECu level, in some part of the active day differences reach above this level particularly in the northern hemisphere mid-latitude and southern hemisphere high latitude stations. In addition maximum differences are observed over the stations located at southern hemisphere high latitude. However for the quiet day, GPS_TEC and empirical models derived TEC data are consistent and correlation coefficient between them are generally over 0.90 . It is interesting to note that although IRI_PLAS model includes the plasmasphere part and better TEC prediction performance is expected comparing to the IRI_2012 model, the superiority of the IRI_PLAS model is not clear in the results. While IRI_PLAS model reveals good performance in TEC representation and mimics the GPS_TEC data at some stations, for others IRI_2012 TEC data are much closer to the observed GPS_TEC. Such conditions are not depend on the latitudinal location of the stations. In addition, the results corresponding to 02.06.2015 exhibit the influence of the seasonal conditions which cause the (GPS_TEC) - (Models_TEC) values positive in the northern hemisphere and negative in the southern hemisphere stations.
Acknowledgements. The authors would like to express their gratitude to the IONOLAB group for providing IRI_PLAS TEC data and ionolabtec software. We also acknowledge the IRI working group for providing IRI_2012 model. We would like to thank to reviewers for their reviews, critical comments and helpful suggestions, which improved the manuscript greatly.

\section{References}

Aggarwal, M. (2011). TEC variability near northern EIA crest and comparison with IRI model Advances in Space Research, 48, 1221-1231,doi:10.1016/j. asr.2011.05.037.

Alcay S., Yigit C.O., Seemala G., Ceylan A. (2014). GPS-Based Ionosphere Modeling: A Brief Review, Fresenius Environmental Bulletin, 23(3a), 815-824.

Adebiyi S.J, Adimula, I.A,Oladipo, O.A. (2016). Characterisation of GPS_TEC in the African equatorial and low latitude region and the regional evaluation of the IRI model. Journal of Atmospheric and Terrestrial Physics, 143-144, 53-70,doi:10.1016/j. jastp.2016.03.003.

Akala, A.O., Somoye, E.O., Adewale, A.O., Ojutalayo, E.W., Karia, S.P., Idolor, R.O., Okoh, D., Doherty, P.H. (2015). Comparison of GPS_TEC observations over Addis Ababa with IRI_2012 model predictions during 2010-2013. Advances in Space Research, 56, 
1686-1698, doi:10.1016/j.asr.2015.07.017.

Anderson, D.N., Mendillo, M., Herniter, B. (1987). A semi-empirical low lattitudeionospheric model. Radio Science, 22(2), 292-306,doi: 10.1029/ RS022i002p00292.

Arikan, F.,Sezen, U., Gulyaeva T.L., Cilibas O. (2015). Online, automatic, ionosphericmaps: IRI_PLASMAP. Advances in Space Research, 55 (8), 21062113, doi:10.1016/j.asr.2014.10.016.

Arikan, F., Erol, C.B.,Arikan, O. (2003), Regularizedestimation ofvertical total electroncontentfrom Global PositioningSystem data,Journal of Geophysical Research, 108(A12), 1469, doi:10.1029/ 2002JA009605.

Arikan, F., Erol, C.B., Arikan, O. (2004), Regularizedestimation of VTEC from GPS data for a desired time period, RadioScience, 39, RS6012, doi:10.1029/2004RS003061.

Balan, N., Otsuka, Y., Tsugawa, T., Miyazaki, S., Ogawa, T., Shiokawa, K.(2002). Plasmaspheric electron content in the GPS ray paths over Japan under magnetically quiet conditions at high solar activity. Earth Planets Space, 54, 71-79, doi:10.1186/ BF03352423.

Bailey G.J., Su Y.Z., Balan, N. (1997). The Sheffield University plasma sphere ionosphere model- a review. Journal of Atmospheric and Terrestrial Physics, 59(13):1541-1552, doi:10.1016/S13646826(96)00155-1.

Bent, R.B., Llewellyn, S.K. (1973). Documentation and description of the Bent ionospheric model. Space and Missile Organisation, Los Angeles, CA, USA.

Bilitza, D. (2001). International Reference Ionosphere 2000. Radio Science, 36, 261-275,doi: 10.1029/2000RS002432.

Bilitza, D. (2015). The international reference ionosphere - status 2013. Advances in Space Research, 55, 1914-1927, doi:10.1016/j.asr.2014.07.032

Cherniak, I.V., Zakharenkova, I.E., Krankowski, A., Shagimuratov, I.I.(2012). Plasmaspheric electron content derived from GPS TEC and FORMOSAT-3/COSMIC measurements: solar minimum condition. Advances in Space Research,50, 427440, doi:10.1016/j.asr.2012.04.002.

Daniell Jr., R.E., Brown, L.D., Anderson, D.N., Fox, M.W., Doherty, P.H., Decker, D.T., Sojka, J.J., Schunk, R.W. (1995). Parameterized ionospheric model: a global ionospheric parameterization based on first principles models. Radio Science, 30 (5), 1499-1510,doi: 10.1029/95RS01826.
Daniell, R.E., Brown, L.D. (1995). PRISM: a parameterized real-time ionospheric specification model version 1.5. Newton: Computational Physics Inc; 1995.

Emery, B.A., Lu, G., Szuszczewicz, E.P., Richmond, A.D., Roble, R.G., Richards, P.G., Miller, K.L., Niciejewski, R., Evans, D.S., Rich, F.J., Denig, W.F., Chenette, D.L., Wilkinson, P., Pulinets, S., O’Loughlin, K.F., Hanbaba, R., Abdu, M., Jiao, P., Igarashi, K., Reddy, B.M. (1996). Assimilative mapping of ionospheric electrodynamics in the thermosphere-ionosphere general circulation model comparisons with global ionospheric and thermospheric observations during the GEM/SUNDIAL period of March 28-29, 1992. Journal of Geophysical Research, 101 (A12), 26681-26696,doi:10.1029/ 96JA01285.

Gulyaeva, T.L., Huang, X.,Reinisch, B.W. (2002).Plasmaspheric extensionof topside electron density profiles, Advances in Space Research., 29(6), 825831,2002.doi:10.1016/S0273-1177(02)00038-8.

Gulyaeva, T.L., Arikan, F., Stanislawska, I. (2011). Inter-hemispheric imaging of the ionosphere with the upgraded IRI_Plas model during the space weather storms, Earth Planets Space, 63 (8), 929939,doi:10.5047/eps.2011.04.007.

Gulyaeva, T.L., Bilitza, D. (2012). Towards ISO Standard Earth Ionosphere and Plasmasphere Model. In: "New Developments in the Standard Model", edited by R.J. Larsen, pp. 1-39, NOVA, Hauppauge, New York.

[Available at https://www.novapublishers.com/catalog/product_info.php?products_id=35812]

Karia, S.P., Patel, N.C., Pathak, K.N.(2015). Comparison of GPS based TEC measurements with the IRI_2012 model for the period of low to moderate solar activity (2009-2012) at the crest of equatorial anomaly in Indian region. Advances in Space Research, 55 (8), 1965-1975,doi.10.1016/j. asr.2014.10.026.

Kumar, S., Tan, E.L., Razul, S.G., See, C.M.S., Siingh, D. (2014). Validation of the IRI_2012 model with GPS-based ground observation over a low-latitude Singapore station. Earth, Planets and Space, 6617,doi: 10.1186/1880-5981-66-17.

Kumar, S., Tan, E.L., Murti, D.S. (2015). Impacts of solar activity on performance of the IRI_2012 model predictions from low to mid latitudes, Earth, Planets and Space, 67, 42,doi: 10.1186/s40623-015-0205-3.

Leong, S.K., Musa, T.A., Omar, K., Subari, M. D., Pathy, N. B., Asillam, M. F. (2014), Assessment of ionosphere models at Banting: Performance of IRI- 
2007, IRI_2012 and NeQuick2 models during the ascending phase of Solar Cycle 24, Advances in Space Research, doi:10.1016/j.asr.2014.01.026.

Liu, Z., Gao, Y. (2004). Ionospheric TEC predictions over a local area GPS reference network, GPS Solut., 8(1), 23-29, doi:10.1007/s10291-004-0082-x.

Misra, P., Enge, P. (2006). Global Positioning System Signals, Measurements, and Performance (second ed.), 0-9709544-1-7, Ganga-Jamuna Press, Lincoln, Massachusetts, USA.

Nayir H., Arikan F., Arikan O., Erol C.B. (2007). Total electron content estimation with Reg-Est,Journal of Geophysical Research: Space Physics, 112(A11), doi: 10.1029/2007JA012459.

Nohutcu, M., Karslioglu M.O., Schmidt M. (2010). B-Spline modeling of VTEC over Turkey using GPS observations, Journal of Atmospheric and Solar-Terrestrial Physics,72, 7-8, 617-624. doi:10.1016/j.jastp.2010.02.022.

Paul, K.S., Das, A., Ray, S., Paul, A. (2016). Characteristics of Total Electron Content (TEC) observed from a chain of stations near the northern crest of the Equatorial Ionization Anomaly (EIA) along $88.5^{\circ} \mathrm{E}$ meridian in India. Journal of Atmospheric and Terrestrial Physics, 137, 17-28, doi:10.1016/j. jastp.2015.11.011.

Rice, D., Sojka, J.J. (2015). Historical comparisons of IRI and early ionograms, Advances in Space Research, 55, 2003-2011, doi:10.1016/j.asr.2014.05.035.

Schaer, S. (1999). Mapping and predicting the Earth's ionosphereusing the global positioning system, Ph.D. dissertation, Universityof Bern, Astronomical Institute.

Scali, J.L., Reinisch, B.W., Richards, P.G., Zhou, Q., Sulzer, M., Swartz, W.E. (1997). Comparison of incoherent scatter radar and Digisonde measurements with field line interhemispheric plasma modeled results at middle and low latitudes. Journal of Geophysical Research, 102 (A4), 7345-7355, doi:10.1029/96JA03520.

Scherliess, L., Schunk, R.W., Sojka. J.J., Thompson, D.C., Zhu, L. (2006). Utah State University Global Assimilation of Ionospheric Measurements GaussMarkov Kalman filter model of the ionosphere: Model description and validation. Journal of Geophysical Research, 111: A11315, doi:10.1029/ 2006JA011712.

Spoelstra, T.A. (1996). A climatology of quiet/disturbed ionospheric conditions derived from 22 years of Westerbork interferometer observations, Journal of Atmospheric and Terrestrial Physics, 58(11),
1229- 1258, doi:10.1016/0021-9169(95)00143-3.

Tariku, Y.A. (2015). TEC prediction performance of the IRI_2012 model over Ethiopia during the rising phase of solar cycle 24 (2009-2011). Earth, Planets and Space, 67:140,doi: 10.1186/s40623-015-0312-1.

Zakharenkova, I.E.,Cherniak, I.V., Krankowski, A.,Shagimuratov, I.I. (2015). Vertical TEC representationby IRI_2012 and IRI Plas models for European mid latitudes. Advances in Space Research, 55, 2070-2076, doi:10.1016/j.asr.2014.07.027.

URL-1 www.ionolab.orgURL-2 http://irimodel.org.

URL-3 http://IRI.gsfc.nasa.gov

URL-4 ftp://ftp.izmiran.ru/pub/izmiran/SPIM/

URL-5 http://www.gfz-potsdam.de/kp-index

URL-6 http://wdc.kugi.kyoto-u.ac.jp/dstdir/index.html

\footnotetext{
*Corresponding author: Salih Alçay

Necmettin Erbakan University, Geomatics Engineering Department, Konya, Turkey; email: salcay@konya.edu.tr.

2017 by Istituto Nazionale di Geofisica e Vulcanologia. All rights reserved
} 